\title{
Association between social capital and depression among older people: evidence from Anhui Province, China
}

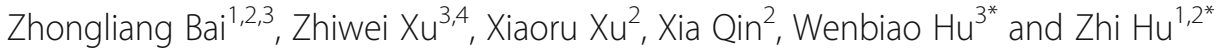

\begin{abstract}
Background: To examine the relationship between social capital and depression among community-dwelling older adults in Anhui Province, China.

Methods: A cross-sectional study was conducted among older people selected from three cities of Anhui Province, China using a multi-stage stratified cluster random sampling method. Data were collected through questionnaire interviews and information on demographic characteristics, social capital, and depression was collected. The generalized linear model and classification and regression tree model were employed to assess the association between social capital and depression.

Results: Totally, 1810 older people aged $\geq 60$ years were included in the final analysis. Overall, all of the social capital dimensions were positively associated with depression: social participation (coefficient: 0.35, 95\% Cl: $0.22-$ 0.48), social support (coefficient:0.18, 95\% Cl:0.07-0.28), social connection (coefficient: 0.76, 95\% Cl:0.53-1.00), trust (coefficient:0.62, 95\% Cl:0.33-0.92), cohesion (coefficient:0.31, 95\% Cl:0.17-0.44) and reciprocity (coefficient:0.30, 95\% Cl:0.11-0.48), which suggested that older people with higher social capital had a smaller chance to develop depression. A complex joint effect of certain social capital dimensions on depression was also observed. The association with depression and the combinative effect of social capital varied among older adults across the cities.

Conclusions: Our study suggests that improving social capital could aid in the prevention of depression among older adults.
\end{abstract}

Keywords: Social capital, Depression, Elderly, Mental health, China

\section{Background}

The proportion of older people ( $\geq 60$ years) in many countries is increasing [1]. China has the highest number of older people in the world with a rapidly aging population [2], and geriatric depression remains a great public health challenge [3]. Recent evidence has suggested approximately one-fifth of older adults in China have

\footnotetext{
* Correspondence: w2.hu@qut.edu.au; aywghz@ahmu.edu.cn

${ }^{3}$ School of Public Health and Social Work, Institute of Health \& Biomedical Innovation, Queensland University of Technology, Brisbane 4059, Australia 'Department of Epidemiology and Biostatistics, School of Public Health, Anhui Medical University, Hefei 230032, China

Full list of author information is available at the end of the article
}

depressive disorders [4]. Depression cannot only impair functional ability, reduce the quality of life and increase the mortality of older adults, but also inflicts a heavy economic burden upon older adults themselves, the society, and the healthcare system [5].

One of the key measures of preventing depression in older people is to identify associated risk factors of depression. Common risk factors of depression include advanced age, female, unfavorable economic levels $[5,6]$. In recent years, increasing studies revealed that older adults are prone to depression if there is an alteration in social roles, social and family settings, and adverse life

(c) The Author(s). 2020 Open Access This article is licensed under a Creative Commons Attribution 4.0 International License, which permits use, sharing, adaptation, distribution and reproduction in any medium or format, as long as you give appropriate credit to the original author(s) and the source, provide a link to the Creative Commons licence, and indicate if changes were made. The images or other third party material in this article are included in the article's Creative Commons licence, unless indicated otherwise in a credit line to the material. If material is not included in the article's Creative Commons licence and your intended use is not permitted by statutory regulation or exceeds the permitted use, you will need to obtain permission directly from the copyright holder. To view a copy of this licence, visit http://creativecommons.org/licenses/by/4.0/. The Creative Commons Public Domain Dedication waiver (http://creativecommons.org/publicdomain/zero/1.0/) applies to the data made available in this article, unless otherwise stated in a credit line to the data. 
events (i.e. diseases or loss of spouse) [7]. With the development of social determinants of health, the role of social capital in the mental health of human beings has been increasingly recognized [8]. Social capital is a multi-faced concept and includes multiple dimensions, each of which is used to describe a phenomenon pertaining to social relations at the individual and societal levels [6,9]. Studies in many countries including China $[6,10-12]$ have shown that social capital is associated with depression in older people and increasing attention has been focused on the effect of social capital on geriatric mental health [13].

However, previous studies looking at the association of social capital with depression among older people used various dimensions to measure social capital and reported inconsistent results. For instance, a study in Korea used trust and reciprocity to measure social capital and suggested that low trust and reciprocity levels were associated with depressive symptoms in older people [6]. Similarly, another study in Korea explored the relationship between social capital (measured with network and trust) and depression among urban older adults and found that trust in social capital was associated with depression, while network was not [14]. A study in China surveyed the association of social capital (assessed with trust, reciprocity, social network, and social participation) with depression among urban older people, and revealed that trust, reciprocity, and social network were significantly associated with depression while social participation was not [11]. Therefore, understanding and comparing the association between social capital depression among older adults across regions requires a standard or highly accepted and validated method to measure social capital.

Although a number of risk factors such as age, female, unfavorable economic levels and social capital, have been investigated in previous research [5-7, 11], it remains unclear if there is a synergistic or antagonistic effect between social capital and other risk factors on depression. In practice, older adults are exposed to two or more risk factors like low economic level and low trust and reciprocity, making them more vulnerable to depression [6]. It is thus needed to investigate how risk factors interact to influence the depression in later life. Knowledge about these findings will yield more tailored and accurate measures to protect older people from depressive disorders.

Therefore, in the current study, we aimed to examine the association of social capital with depression in older adults in China. Specifically, we first examined whether six social capital dimensions in this study were associated with depression and then further explored the joint effect of social capital and other common risk factors on depression.

\section{Methods}

\section{Study population and data collection}

According to the statistics of Anhui Statistics Bureau in 2016 [15], the gross domestic product (GDP) per capita was CNY (Chinese yuan, 1 US \$ equals about CNY 7.10) 80,138 for Hefei, CNY 40,740 for Xuancheng, and CNY 17,642 for Fuyang. In addition, among sixteen cities of Anhui Province, Hefei, Xuancheng, and Fuyang ranked first, eighth, and last, respectively, in GDP per capita. These three cities were selected in this study. Based on the geographic location and economic levels [15], a multi-stage stratified cluster random sampling method was employed to recruit participants in order to have a representative sample. At the first stage, we selected three prefecture-level cities from the sixteen prefecturelevel cities in Anhui province, China: Fuyang (north, lower economic level); Xuancheng (south, middle economic level); Hefei (central, higher economic level, the capital city of Anhui). Then, in each prefecture-level city, one county and one district were selected randomly. A total of six counties and districts were selected in this study. Next, in each selected county and district, one street community and one township were randomly selected and a total of 12 street communities and townships were used as sample sites for this study. Lastly, in each selected street community and township, two communities and two villages were selected randomly and 24 sampling areas were ascertained (Fig. 1). More information about our sampling process can also be founded elsewhere [16].

Between July and September 2017, we conducted cross-sectional surveys in these 24 sampling areas. Based on the local household registry, individuals aged $\geq 60$ years were determined. Aided by local community workers, skilled and trained graduate students from Anhui Medical University visited each participant and conducted face to face interviews using a structured questionnaire. The participants received a verbal description of the purposes and procedures of the study and informed consent is needed before the interview. The process of data collection took about $40 \mathrm{~min}$. Each respondent was compensated with a gift of about 2 US dollars (CNY 15) for the time and cooperation after the interview. Individuals who were not able to carry out proper verbal communication, due to being deaf or mute and dementia or cognitive impairments, were excluded. In the present study, 1935 older adults were interviewed, of which 1810 (93.54\%) were eligible for analysis, with 567 in Fuyang, 603 in Xuancheng, and 640 in Hefei, respectively.

\section{Measurement of social capital}

Based on the framework of the World Bank's Social Capital Assessment Tool and previous works of our 


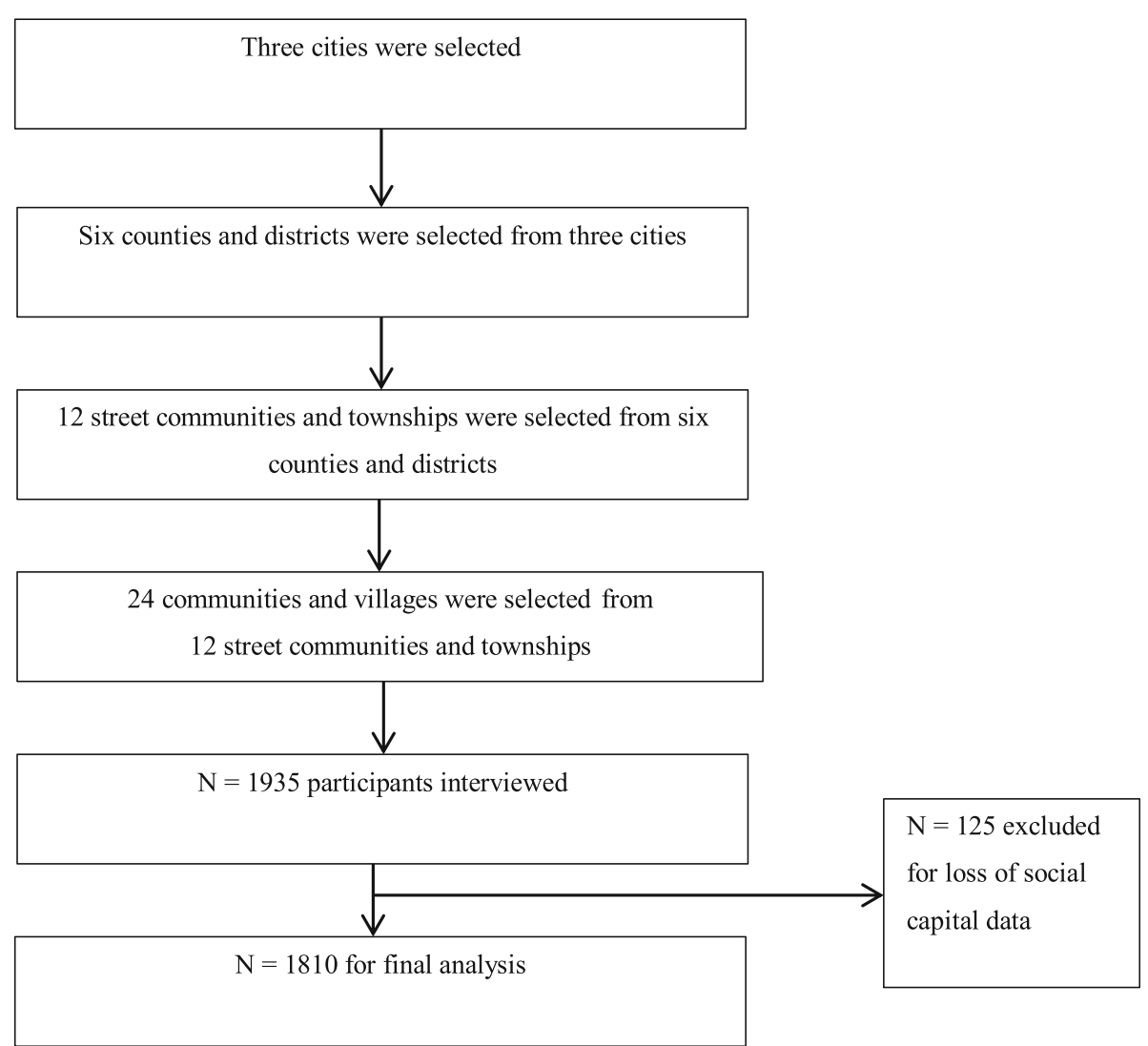

Fig. 1 The flowchart of the sampling process

research group [9, 16-18], six dimensions of social capital were included in the present study: social participation, social support, social connection, trust, cohesion, and reciprocity. We selected 22 commonly used and easily understandable items to measure social capital and adapted them to the Chinese context. In the present study, the five-point Likert scale was adopted in the social capital questionnaire, and respondents were asked to rate their agreement (1"never", 2 "seldom", 3 "usually", 4 "often", and 5 "more often"). The measurement of social capital has also been described elsewhere [16] and more detailed information about the questionnaire can be found in the supplementary file (Additional file 1).

For each domain of social capital, answers to the items were summated to obtain an overall score with higher scores indicating better social capital status. Construct validity was tested to estimate the validity of our instrument by exploring the correlations of each item of social capital dimension and the scores of social capital dimensions, respectively, where large effect size (correlation coefficient $\geq 0.50$ ) was observed in all magnitude [19], indicating construct validity of our instrument. Internal consistency was calculated to prove the reliability of the measurement tool. Cronbach's $\alpha$ of the questionnaire was 0.919 , showing an excellent internal consistency for our scale with this specific sample. For each dimension, Cronbach's $\alpha$ for social participation, social support, social connection, trust, cohesion, and reciprocity was $0.752,0.921,0.767,0.883,0.940$, and 0.869 , respectively.

\section{Measurement of depressive symptoms}

The Zung Self-Rating Depression Scale (SDS), a widely used screening tool for depressive feelings [20, 21], was adopted to assess the depression status of the participants. Construct validity was tested to estimate the validity of our instrument by exploring the correlations of each item of the scale and the scores of depression. The correlation coefficient ranges from 0.682 to 0.888 , which shows a large effect size (correlation coefficient $\geq 0.50$ ) [19], indicating a good validity of our instrument. Cronbach's $\alpha$ of the scale was 0.965 , indicating excellent internal consistency in this sample.

In this study, we selected 16 items to measure depression of older adults, which were more understandable and acceptable for the Chinese community older dwellers. We summated the items to calculate the total depression score, ranging from 16 to 64, with higher scores indicating a lower likelihood of depression. 
Table 1 Descriptive analysis results of participants characteristics $(N=1810)$

\begin{tabular}{|c|c|c|c|c|}
\hline Variables & $\begin{array}{l}\text { Total } \\
\mathrm{N}=1810^{*}\end{array}$ & $\begin{array}{l}\text { Fuyang } \\
N=567\end{array}$ & $\begin{array}{l}\text { Xuancheng } \\
N=603^{*}\end{array}$ & $\begin{array}{l}\text { Hefei } \\
N=640\end{array}$ \\
\hline Age (years), range (60-96) & $70.00 \pm 7.51$ & $70.47 \pm 7.55$ & $70.65 \pm 7.24$ & $72.37 \pm 7.60$ \\
\hline $60-64$ & $399(22.0)$ & $146(25.7)$ & $139(23.1)$ & $114(17.8)$ \\
\hline $65-69$ & $424(23.4)$ & $138(24.3)$ & $154(25.5)$ & $132(20.6)$ \\
\hline $70-74$ & $421(23.3)$ & $119(21.0)$ & $143(23.7)$ & $159(24.8)$ \\
\hline$\geq 75$ & $566(31.3)$ & $164(28.9)$ & $167(27.7)$ & $235(36.7)$ \\
\hline \multicolumn{5}{|l|}{ Gender } \\
\hline Male & $770(42.5)$ & $220(38.8)$ & $277(45.9)$ & $273(42.7)$ \\
\hline Female & $1040(57.5)$ & $347(61.2)$ & $326(54.1)$ & $367(57.3)$ \\
\hline BMI $\left(\mathrm{kg} / \mathrm{m}^{2}\right)$, range (14.5-45.9) & $22.72 \pm 3.44$ & $23.48 \pm 3.65$ & $22.13 \pm 3.30$ & $22.59 \pm 3.27$ \\
\hline \multicolumn{5}{|l|}{ Residence } \\
\hline Urban & $801(44.3)$ & $249(43.9)$ & $218(36.2)$ & $334(52.2)$ \\
\hline Rural & 1009 (55.7) & $318(56.1)$ & 385 (63.8) & $306(47.8)$ \\
\hline \multicolumn{5}{|l|}{ Living status } \\
\hline Living alone & $243(13.4)$ & 66 (11.6) & $72(11.9)$ & $105(16.4)$ \\
\hline Living with others & $1567(86.6)$ & $501(88.4)$ & $531(88.1)$ & $535(83.6)$ \\
\hline \multicolumn{5}{|l|}{ Marital status } \\
\hline Married / cohabited & $1402(77.5)$ & $440(77.6)$ & $475(78.8)$ & $487(76.1)$ \\
\hline Never married / divorced & $19(1.0)$ & $4(0.7)$ & $8(1.3)$ & $7(1.1)$ \\
\hline Widowed & $389(21.5)$ & $123(21.7)$ & $120(19.9)$ & $146(22.8)$ \\
\hline \multicolumn{5}{|l|}{ Education } \\
\hline Primary school and below & $1291(71.3)$ & $439(77.4)$ & $463(76.8)$ & $389(60.8)$ \\
\hline Junior high school & $291(16.1)$ & $72(12.7)$ & $75(12.4)$ & $144(22.5)$ \\
\hline High school & $163(9.0)$ & $45(7.9)$ & $48(8.0)$ & $70(10.9)$ \\
\hline College and above & $65(3.6)$ & $11(1.9)$ & $17(2.8)$ & $37(5.7)$ \\
\hline \multicolumn{5}{|l|}{ Smoking status } \\
\hline Smoking-quitter & $99(5.5)$ & $29(5.1)$ & $40(6.6)$ & $30(4.7)$ \\
\hline Smoker & $299(16.5)$ & $93(16.4)$ & $130(21.6)$ & 76 (11.9) \\
\hline Non-smoker & $1412(78.0)$ & $445(78.5)$ & $433(71.8)$ & $534(83.4)$ \\
\hline \multicolumn{5}{|l|}{ Drinking status } \\
\hline Drinking-quitter & $70(3.9)$ & $33(5.8)$ & $15(2.5)$ & $22(3.4)$ \\
\hline Drinker & $256(14.1)$ & $68(12.0)$ & $102(16.9)$ & 86 (13.4) \\
\hline Non-drinker & $1484(82.0)$ & $466(82.2)$ & $486(80.6)$ & $532(83.1)$ \\
\hline Social participation, range (4-20) & $7.34 \pm 3.80$ & $5.95 \pm 2.67$ & $6.94 \pm 3.36$ & $8.95 \pm 4.40$ \\
\hline Social support, range (4-20) & $12.06 \pm 5.29$ & $11.91 \pm 5.46$ & $12.04 \pm 4.71$ & $12.20 \pm 5.64$ \\
\hline Social connection, range (3-15) & $12.20 \pm 2.49$ & $12.23 \pm 2.29$ & $12.10 \pm 2.70$ & $12.27 \pm 2.47$ \\
\hline Trust, range (3-15) & $12.89 \pm 2.30$ & $12.96 \pm 2.16$ & $12.54 \pm 2.48$ & $13.15 \pm 2.20$ \\
\hline Cohesion, range (5-25) & $19.36 \pm 4.73$ & $19.89 \pm 4.08$ & $18.12 \pm 5.19$ & $20.06 \pm 4.59$ \\
\hline Reciprocity, range (3-15) & $10.54 \pm 3.36$ & $10.28 \pm 3.53$ & $10.43 \pm 3.42$ & $10.88 \pm 3.12$ \\
\hline Depression, range (16-64) & $49.13 \pm 11.30$ & $46.13 \pm 12.54$ & $49.03 \pm 12.54$ & $51.87 \pm 9.57$ \\
\hline
\end{tabular}

Note: * continuous variables are presented as range and mean \pm standard deviation, categorical variables are presented as number (\%)

Assessment of demographic variables

Information on the demographic and health-related variables was collected. These variables included age (60-64, 65-69, 70-74, $\geq 75$, years), gender (male, female), body mass index (BMI, $\mathrm{kg} / \mathrm{m}^{2}$ ), residence (urban, rural), living status (living alone, living with spouse/children/grandchildren and else), marital status (married/cohabited, never married/divorced, widowed), and education 
Table 2 The relationship between social capital and depression using GLM

\begin{tabular}{|c|c|c|c|c|c|c|c|}
\hline & & Unadjusted & & & Adjusted & & \\
\hline & Social capital dimensions & $B(S . E)$. & $95 \% \mathrm{Cl}$ & $p$-Value & $B(S . E)$. & $95 \% \mathrm{Cl}$ & $p$-Value \\
\hline \multirow[t]{6}{*}{ Overall } & Social participation & $0.88(0.07)$ & $0.75-1.01$ & $<0.001$ & $0.35(0.07)$ & $0.22-0.48$ & $<0.001$ \\
\hline & Social support & $0.73(0.05)$ & $0.64-0.83$ & $<0.001$ & $0.18(0.05)$ & $0.07-0.28$ & 0.001 \\
\hline & Social connection & $1.83(0.10)$ & $1.64-2.02$ & $<0.001$ & $0.76(0.12)$ & $0.53-1.00$ & $<0.001$ \\
\hline & Trust & $2.11(0.10)$ & $1.90-2.31$ & $<0.001$ & $0.62(0.15)$ & $0.33-0.92$ & $<0.001$ \\
\hline & Cohesion & $1.01(0.05)$ & $0.91-1.11$ & $<0.001$ & $0.31(0.07)$ & $0.17-0.44$ & $<0.001$ \\
\hline & Reciprocity & $1.31(0.07)$ & $1.17-1.46$ & $<0.001$ & $0.30(0.09)$ & $0.11-0.48$ & 0.001 \\
\hline \multirow[t]{6}{*}{ Fuyang } & Social participation & $1.15(0.19)$ & $0.78-1.53$ & $<0.001$ & $0.36(0.18)$ & $0.00-0.71$ & 0.048 \\
\hline & Social support & $0.88(0.09)$ & $0.71-1.05$ & $<0.001$ & $0.26(0.11)$ & $0.04-0.49$ & 0.022 \\
\hline & Social connection & $2.30(0.21)$ & $1.89-2.71$ & $<0.001$ & $0.76(0.27)$ & $0.24-1.29$ & 0.004 \\
\hline & Trust & $2.66(0.22)$ & $2.24-3.09$ & $<0.001$ & $0.76(0.33)$ & $0.10-1.41$ & 0.023 \\
\hline & Cohesion & $1.52(0.11)$ & $1.30-1.74$ & $<0.001$ & $0.63(0.18)$ & $0.29-0.98$ & $<0.001$ \\
\hline & Reciprocity & $1.42(0.14)$ & $1.15-1.68$ & $<0.001$ & $0.08(0.19)$ & $-0.29-0.44$ & 0.688 \\
\hline \multirow[t]{6}{*}{ Xuancheng } & Social participation & $0.75(0.13)$ & $0.50-1.01$ & $<0.001$ & $0.26(0.13)$ & $0.00-0.52$ & 0.051 \\
\hline & Social support & $0.61(0.09)$ & $0.43-0.79$ & $<0.001$ & $0.09(0.10)$ & $-0.10-0.28$ & 0.354 \\
\hline & Social connection & $1.60(0.15)$ & $1.30-1.90$ & $<0.001$ & $0.86(0.20)$ & $0.47-1.25$ & $<0.001$ \\
\hline & Trust & $1.75(0.17)$ & $1.42-2.08$ & $<0.001$ & $0.30(0.25)$ & $-0.19-0.80$ & 0.231 \\
\hline & Cohesion & $0.80(0.08)$ & $0.64-0.96$ & $<0.001$ & $0.27(0.11)$ & $0.06-0.48$ & 0.011 \\
\hline & Reciprocity & $1.26(0.12)$ & $1.03-1.50$ & $<0.001$ & $0.44(0.16)$ & $0.12-0.76$ & 0.008 \\
\hline \multirow[t]{6}{*}{ Hefei } & Social participation & $0.63(0.08)$ & $0.47-0.80$ & $<0.001$ & $0.16(0.08)$ & $0.00-0.32$ & 0.050 \\
\hline & Social support & $0.67(0.06)$ & $0.55-0.79$ & $<0.001$ & $0.18(0.07)$ & $0.04-0.32$ & 0.010 \\
\hline & Social connection & $1.73(0.14)$ & $1.46-2.00$ & $<0.001$ & $0.65(0.16)$ & $0.32-0.97$ & $<0.001$ \\
\hline & Trust & $2.03(0.15)$ & $1.73-2.32$ & $<0.001$ & $0.77(0.21)$ & $0.37-1.17$ & $<0.001$ \\
\hline & Cohesion & $0.99(0.07)$ & $0.85-1.13$ & $<0.001$ & $0.43(0.10)$ & $0.23-0.62$ & $<0.001$ \\
\hline & Reciprocity & $1.12(0.11)$ & $0.90-1.34$ & $<0.001$ & $0.06(0.13)$ & $-0.20-0.31$ & 0.675 \\
\hline
\end{tabular}

Note: Adjusted by age, gender, BMI, residence, living status, marital status, education, smoking, and drinking status

B: regression coefficient

S.E.: standard error

95\% Cl: confidence interval of $95 \%$

(primary school and below, junior high school, high school, college and above). Information on smoking and drinking status was also collected.

\section{Statistical analysis}

Continuous variables were presented as mean \pm standard deviation and range, categorical variables were presented as number (\%). A general linear model (GLM) was used to initially investigate the relationship between different social capital dimensions and depression scores. The GLM model can be specified as follows:

$$
\begin{aligned}
& \text { Depression scores } \approx \alpha+\beta_{1} \text { Social capital dimensions } \\
& \quad+\beta_{2} \text { Confounders } s_{1}+\ldots+\beta_{n} \text { Confounders }_{n}
\end{aligned}
$$

where depression score is the dependent variable; $\alpha$ is the intercept; social capital dimensions refer to the above-mentioned six dimensions of social capital and $\beta_{1}$ is the corresponding coefficient; $\beta_{2}$ Confounders $_{1}+$ $\ldots+\beta_{n}$ Confounders $_{n}$ indicate potential confounders in the model and their corresponding coefficients were $\beta_{2} \ldots \beta_{n}$. In this model, we considered age, gender, body mass index, residence, living status, marriage status, education, smoking, and drinking status as potential confounders as previous studies have shown that these confounders are associated with depression in later life $[4,5,22,23]$. Other confounders such as shorter sleeping time and physical disability [23] were not included as no data was available for this study. Collinearity between all independent variables was not existing according to the variance inflation factor (VIF) results (Additional file 2). At last, to explore the combinative relationship between social capital and depression, a classification and regression tree (CART) model was developed by dividing all social capital dimensions (social participation, social support, social connection, trust, cohesion, and reciprocity) and demographic variables into subsets. The classification and regression tree (CART) 


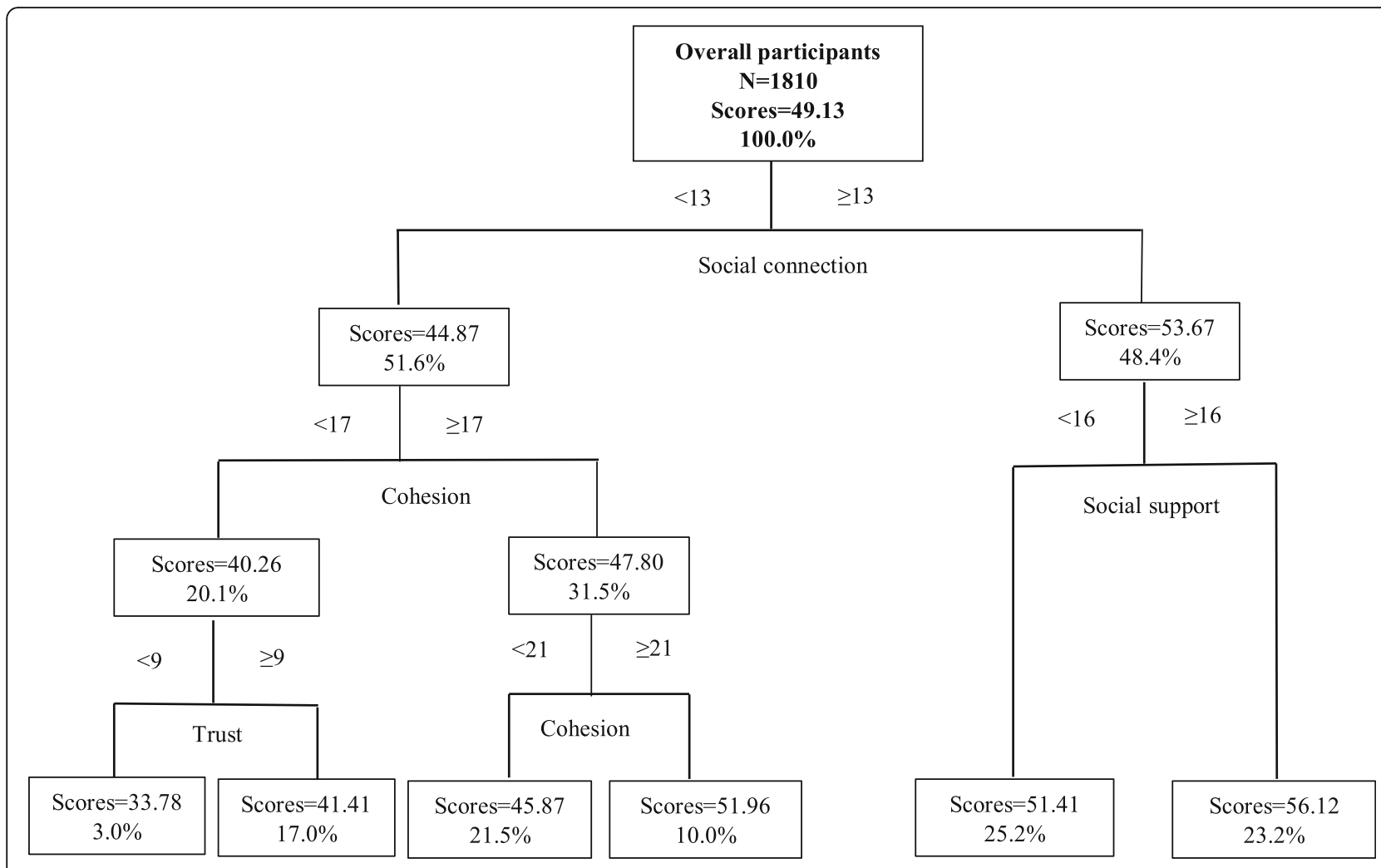

Scores: depression mean scores

Fig. 2 CART results of social capital and depression $(N=1810)$

model is a flexible, robust, and non-parametric model that was previously used in depression disease study [24, 25]. The best model is defined as having the smallest tree size and an estimated error rate within one standard error of the minimum [26]. The GLM model and CART model were stratified according to the economic levels separately. All statistical analyses were performed with SPSS statistics software, version 23 (SPSS Inc.; Chicago, IL, USA) and $\mathrm{R}$ version 3.4.0. $P<0.05$ was considered statistically significant.

\section{Results}

\section{Results of descriptive analysis}

They included 770 males (42.5\%) and 1040 females $(57.5 \%)$ and their mean age was $71.20 \pm 7.51$ years (range 60 to 96 ). Rural residents accounted for $55.7 \%$ of the population and $71.66 \%$ of the participants did not live alone. In addition, $77.5 \%$ of respondents were married or cohabited, $71.3 \%$ of participants attended primary school and below, and the majority of respondents were nonsmokers (78.0\%) and non-drinkers (82.0\%). (Table. 1).

\section{Results of the GLM model}

As shown in Table 2, after controlling for confounders, the effects of six dimensions of social capital became attenuated but were positively associated with depression. Specifically, in the total population, with each social capital dimension increased one score, depression scores increased by $0.35,0.18,0.76,0.62,0.31,0.30$, respectively. However, in cities of different economic levels, social capital dimensions related to depression were varied. In Fuyang (lower economic level), all dimensions were statistically associated with depression, except for reciprocity. In Xuancheng (middle economic level), social connection, reciprocity, and cohesion were positively associated with depression. Meanwhile, social participation, social support, and trust were not statistically related to depression. In Hefei (higher economic level), social support, social connection, trust, and cohesion were positively associated with depression while social participation and reciprocity were not statistically significant.

\section{Results of the CART model}

The joint effect of social capital was observed (Fig. 2). Social connection was the first classifying dimension. Thus, social connection was the most important dimension of social capital and was associated with depression among older people. Overall, older adults whose social connection score was $\geq 13$, and social support score 


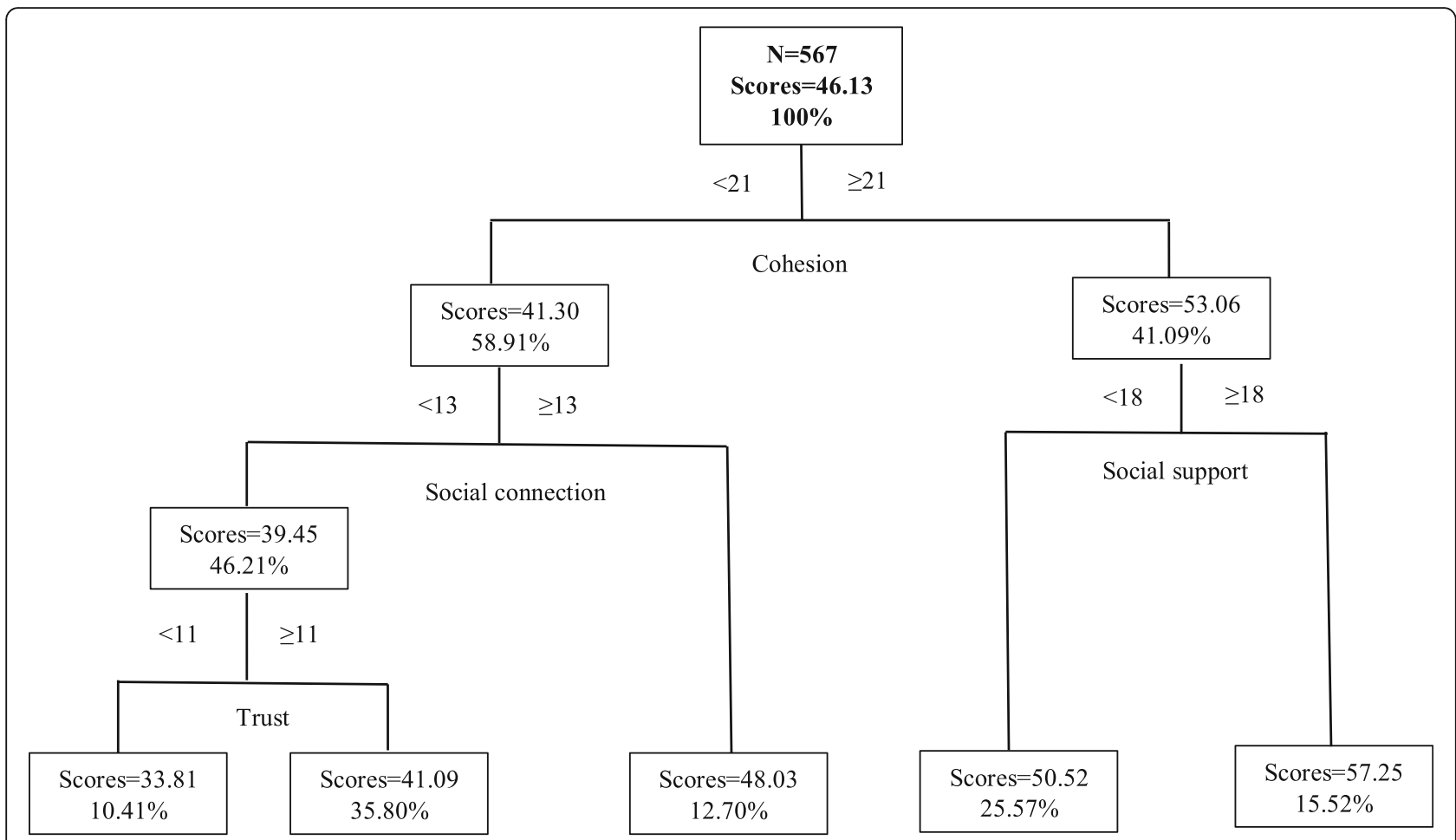

Scores: depression mean scores

Fig. 3 CART results of social capital and depression in Fuyang $(N=567)$

were $\geq 16$ showed an increase of 6.99 in the mean depression scores (from 49.13 to 56.12). Such a joint effect of social capital related to depression also varied among older people from areas of different economic levels. (Figs. 3, 4 and 5).

Cohesion was the first classifying factor. Thus, this factor was the most associated with depression among older people in the lower economic level city (Fuyang). Among those participants with higher cohesion score $(\geq$ 21 ) and social support score $(\geq 18)$, the mean depression scores increased by 11.12 (from 46.13 to 53.06) in comparison to those with lower cohesion and social support scores (Fig. 3).

For older people in the middle economic level area (Xuancheng), reciprocity was the first classifying factor. The results suggested that older adults with higher reciprocity score $(\geq 7)$, social connection score $(\geq 13)$, and cohesion score $(\geq 21)$ were less likely to report geriatric depression, along with an increase of 7.57 in the depression score (from 49.03 to 56.60) (Fig. 4).

Among older people in the higher economic level city (Hefei), trust was the first classifying dimension, which was mostly associated with depression. Participants whose trust score $\geq 13$ and social connection score $\geq 15$ had higher depression scores (from 51.87 to 57.72 ) (Fig. 5).

\section{Discussion}

The present study examined the relationship of social capital with depression in later life from a representative sample in Anhui, China. The results revealed the correlation of social capital with geriatric depression and the joint effect of certain social capital dimensions on depressive symptoms. Moreover, such findings persisted when separated by different economic level areas.

We found that a higher level of social capital was associated with a lower likelihood of experiencing depressive symptoms after adjustment for confounders in the total population, which is consistent with previous studies [6, 10, 11, 27]. Li et al. [10] and Han et al. [6] showed that a lower level of social capital (concerning trust and reciprocity) was connected associated with suffering from depression among people in their later life. In line with a prior study [28], we also found social connection could reduce the risk of depression among older adults. Similar to our findings, Haseda et al. [29] suggested that more exchanges in social support were associated with a lower risk of depression, especially among male older adults. We also observed that older people with more cohesion were less likely to have depression, which is consistent with previous findings [28, 30, 31]. However, different from our findings, a 


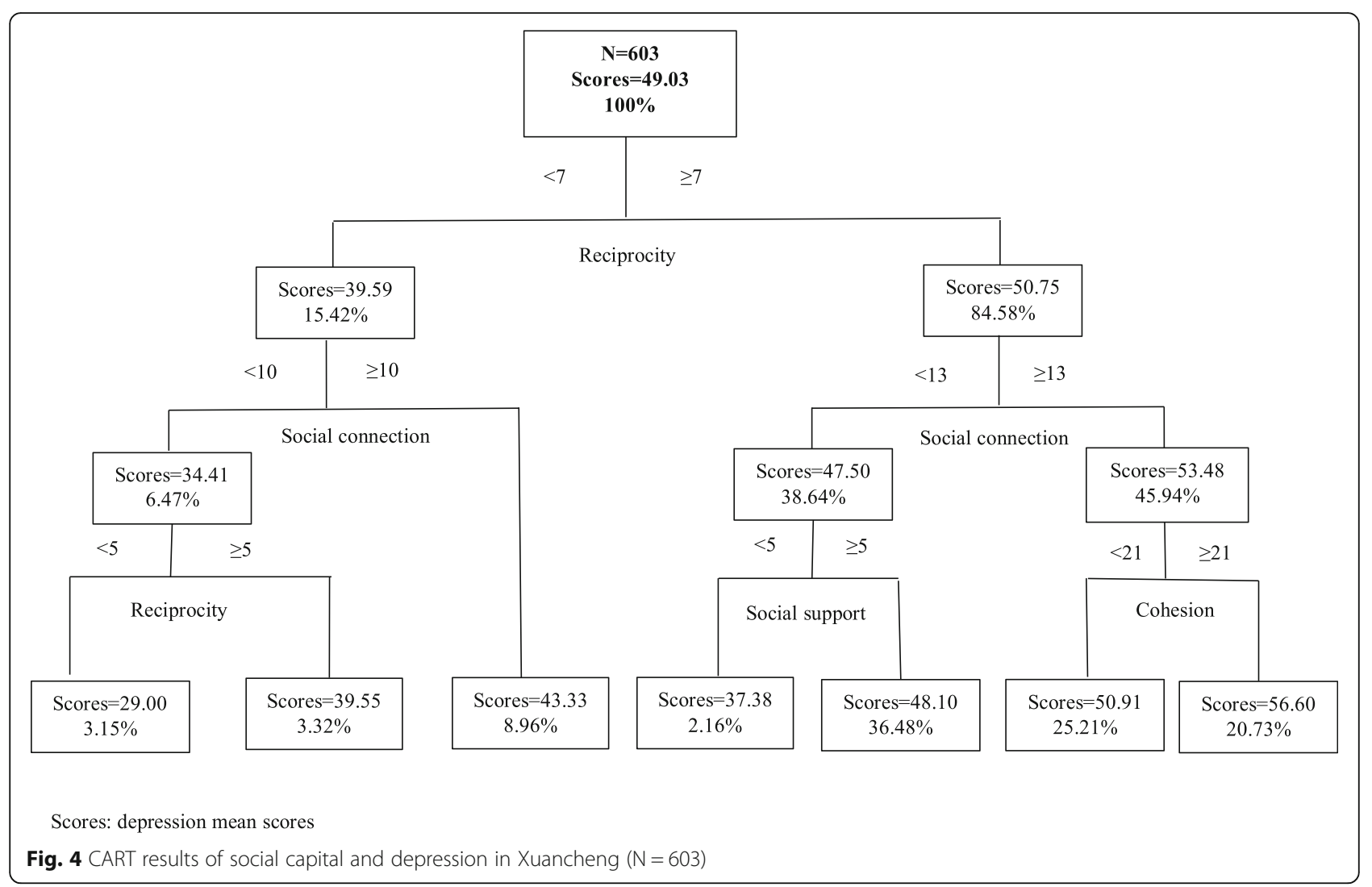

previous study found no association between social participation and depression [11]. One possible reason for this inconsistency may be that physical function wellness has been proven to influence the association of social participation with depression among older people $[11,31,32]$. Thus, more study is needed to further examine this conclusion in the future.

We also observed that certain dimensions of social capital matter for depression among older people at different economic level cities. Specifically, social capital in terms of social participation, social support, social connection, trust, and cohesion is statistically correlated with depressive symptoms among older adults from a lower economic level area. Meanwhile, social capital regarding social connection, cohesion, reciprocity is found to be associated with depression among older people from a middle economic level area. Finally, social capital concerning social support, social connection, trust, and cohesion is significant for older people from an area with a higher economic level. To our knowledge, this is the first study to explore the association between social capital and depression among older adults stratified by different economic levels. This mixed pattern of associations reveals that certain dimensions of social capital play a role across the economic level, which further highlights that economic levels play a significant role in constructing and building social capital [33, 34].
The significance of this finding indicates that social capital should be included when taking measures to address the issues of depression among older people and adds to the limited literature on the disparity in social capital in areas of different economic levels. In addition, this underscores the necessity to assess social capital with several dimensions instead of just one single dimension [9].

Another significant finding of this study is the joint effect of certain dimensions of social capital on depression. In the total population, older adults who had greater social participation and social support were less likely to develop depression. Similarly, such a joint effect also varied among older people from areas of different economic levels. That is, older people from an area of a lower economic level who reported greater cohesion and social support were prone to be depression-free. By contrast, older people residing in an area of middle economic level who reported greater reciprocity, social connection, and cohesion were less likely to experience depressive symptoms. Meanwhile, older adults from an area of higher economic level who had greater trust and social connection were less likely to have depression. Similar to our results, a previous study also suggested that older adults living in lower socioeconomic status locations prefer to communicate and interact with neighbors, thus generating higher social cohesion which is good for depression prevention [35]. Besides, in China, 


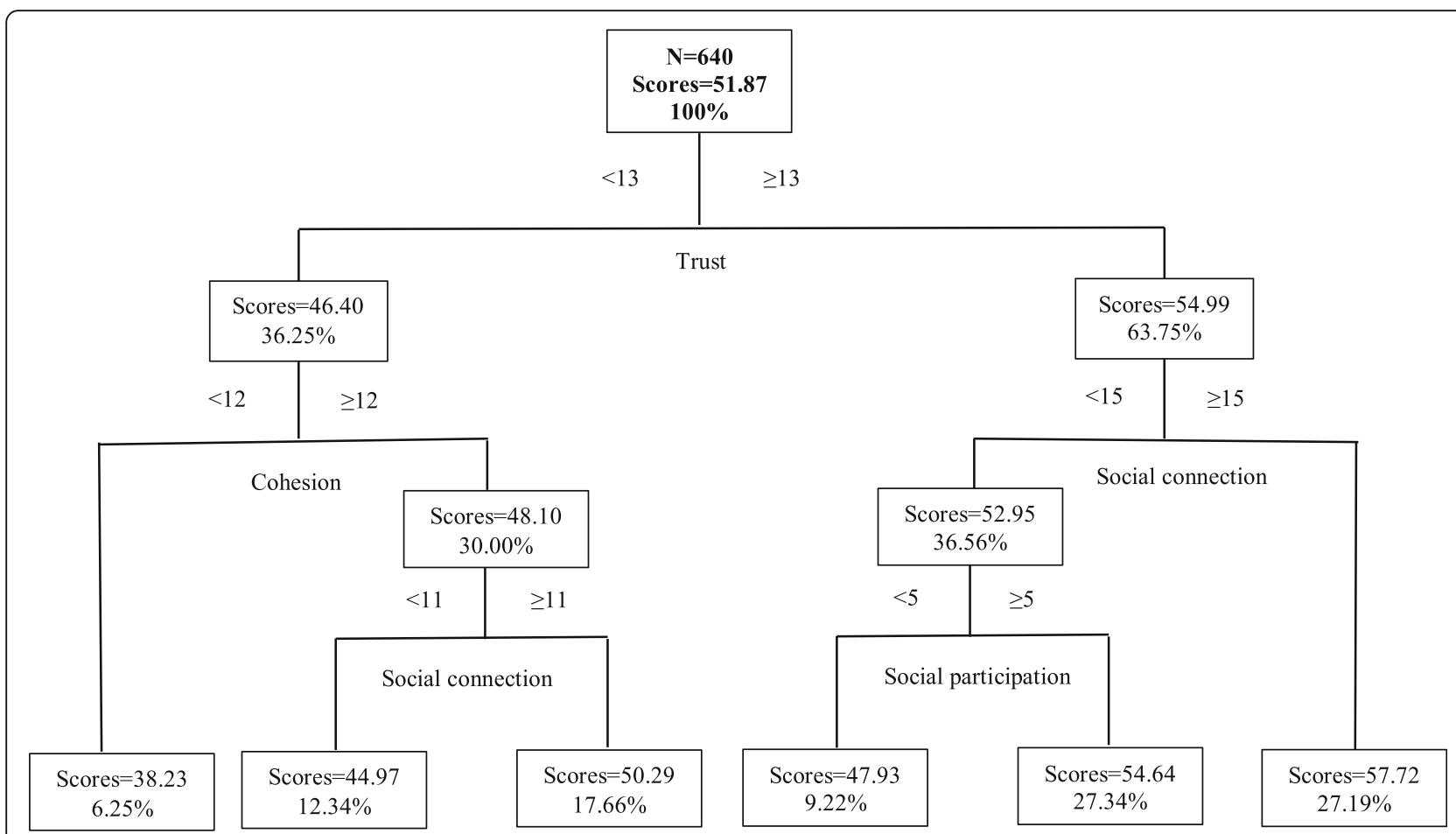

Scores: depression mean scores

Fig. 5 CART results of social capital and depression in Hefei $(N=640)$

poor areas are the core of help measures under the national policy "Poverty Alleviation" in the past decades; as a result, people in these areas can get help and support from various channels [36]. Previous studies also concluded that older individuals with worse reciprocity and social connection had a higher risk of depression $[6,31$, 37], but they did not categorize older people with a middle economic level, and more evidence is needed to examine the association between social capital and depression within a region with different economic statuses. Likewise, a study found that older people living in a higher economic community with greater trust with family members were less likely to be depressed $[6,38]$. By looking at these findings, we reconfirmed the significant role of social capital in maintaining the mental health of older populations, which is in line with previous studies $[6,11]$ and broadens our understanding of the role of social capital across areas of different economic levels.

Previous studies have found that economic levels are also of importance for the health of an individual as higher economic levels are associated with better utilization of public resources and facilities and a more sound social welfare system, which confer benefits on less likely to experience depression [33, 39]. Besides, some factors of a region including economic levels have been found to influence the construction and building of social capital [33], and pathways that connect social capital with health may vary in different economic settings [34]. Therefore, when linking social capital to health outcomes, economic levels should be well considered [39].

Some suggestions for preventing the onset of depression in later life can be provided based on our results. First, variations in possession of certain dimensions of social capital by economic levels may have implications for devising programs that aim at preventing depression and suggest that such programs should be compatible with the economic setting of a region. Besides, to maximize the function of social capital in maintaining mental wellness, measures including certain social capital should take the joint effect of social capital into account. For example, more attention should be paid to social connection and social support when devising measures to reduce the risk of being depressed among older people.

However, the study has several limitations. First, this is a cross-sectional study, which could not provide sufficient evidence to establish causality. Second, the subjects of this study were only selected from three cities in Anhui province, and the results may not apply to other regions in China. Third, there is no commonly used measurement tool of social capital, which makes the 
comparison with other studies difficult. Lastly, another limitation is that the confounders in this study were not comprehensive enough (e.g., economic level, alteration in social roles, social and family settings, adverse life events [7], and physical disability [23]).

Nevertheless, this study has some strengths. First, our study has explored the relationship between social capital and geriatric depression using a representative sample status with a good response rate in Anhui, China. Our results provide important evidence concerning the role of social capital on depression. Second, the study used simple, reliable, valid assessment tools to obtain data about social capital; Also, the CART model found a joint effect of social capital on depression, which implies that a comprehensive and complex analytical method could be used to design more accurate and specific measures to reduce the incidence of depression in later life.

\section{Conclusions}

The present study provides evidence on the relationship between social capital and geriatric depression shows that social capital is associated with depression. Specifically, in areas of lower socioeconomic level, older people with better cohesion and social support results were less likely to have depression. Meanwhile, in the middle economic level areas, individuals who had lower reciprocity and social connection scores were more prone to have depression. In the higher economic level areas, older adults whose trust and social connection scores were higher were more likely to be mentally healthy.

\section{Supplementary information}

Supplementary information accompanies this paper at https://doi.org/10 1186/s12889-020-09657-7.

Additional file 1. Social capital and elderly depression questionnaire (English version), detailed information about the measurement tool.

Additional file 2. Results of collinearity analysis.

\section{Abbreviations}

GDP: Gross Domestic Product; CNY: Chinese yuan; SDS: The Zung Self-Rating Depression Scale; BMI: Body Mass Index; GLM: General Linear Model; VIF: Variance Inflation Factor; CART: Classification And Regression Tree

\section{Acknowledgements}

The authors would like to express sincere appreciation for the participants and the support of the Australia China Center for Public Health (ACCPH).

\section{Authors' contributions}

$\mathrm{XQ}$ and $\mathrm{ZH}$ conceived and designed the study. ZB undertook data collection, performed statistical analyses, and drafted the manuscript. XX undertook data collection. ZX, XQ, ZH, and WH revised the manuscript. All authors checked, interpreted results, and approved the final version.

\section{Funding}

This work was supported by the National Natural Science Foundation of China (No.71573002 and 71673002). This organization had no role in the research design, data collection, data analysis, manuscript writing, and submission.

\section{Availability of data and materials}

The datasets generated during and/or analyzed during the current study are available from the corresponding author on reasonable request.

\section{Ethics approval and consent to participate}

A written informed consent with a signature was obtained from all participants in our study. For those who could not write, a fingerprint was replaced instead after the participants have fully understood the information mentioned in the informed consent and agreed to take part in this study as a study subject. The procedure was approved and Ethical approval for this study was obtained from the Biomedical Ethics Committee, Anhui Medical University (No. 20150297).

\section{Consent for publication}

Not applicable.

\section{Competing interests}

The authors declare that they have no competing interests.

\section{Author details}

1Department of Epidemiology and Biostatistics, School of Public Health, Anhui Medical University, Hefei 230032, China. ${ }^{2}$ Department of Health Services Management, School of Health Services Management, Anhui Medical University, Hefei 230032, China. ${ }^{3}$ School of Public Health and Social Work, Institute of Health \& Biomedical Innovation, Queensland University of Technology, Brisbane 4059, Australia. ${ }^{4}$ School of Public Health, Faculty of Medicine, University of Queensland, Brisbane 4059, Australia.

Received: 14 July 2020 Accepted: 8 October 2020

Published online: 16 October 2020

\section{References}

1. WHO: World report on ageing and health. In.: World Health Organization; 2015.

2. Bartels SJ. Why collaborative care matters for older adults in China. Lancet Psychiatry. 2015;2(4):286-7.

3. Chen S, Conwell Y, He J, Lu N, Wu J. Depression care management for adults older than 60 years in primary care clinics in urban China: a clusterrandomised trial. Lancet Psychiatry. 2015;2(4):332-9.

4. Zhong B-L, Ruan Y-F, Xu Y-M, Chen W-C, Liu L-F. Prevalence and recognition of depressive disorders among Chinese older adults receiving primary care: a multi-center cross-sectional study. J Affect Disord. 2020;260: 26-31.

5. Chen R, Wei L, Hu Z, Qin X, Copeland JR, Hemingway H. Depression in older people in rural China. Arch Intern Med. 2005;165(17):2019-25.

6. Han KM, Han C, Shin C, Jee HJ, An H, Yoon HK, Ko YH, Kim SH. Social capital, socioeconomic status, and depression in community-living elderly. J Psychiatr Res. 2018;98:133-40.

7. Zhang Y, Chen Y, Ma L. Depression and cardiovascular disease in elderly: current understanding. J Clin Neurosci. 2018;47:1-5.

8. Ehsan AM, De Silva MJ. Social capital and common mental disorder: a systematic review. J Epidemiol Community Health. 2015;69(10):1021-8.

9. Ma Y, Qin X, Chen R, Li N, Chen R, Hu Z. Impact of individual-level social capital on quality of life among AIDS patients in China. PLoS One. 2012; 7(11):e48888.

10. Li Q, Zhou X, Ma S, Jiang M, Li L. The effect of migration on social capital and depression among older adults in China. Soc Psychiatry Psychiatr Epidemiol. 2017;52(12):1513-22.

11. Cao W, Li L, Zhou X, Zhou C. Social capital and depression: evidence from urban elderly in China. Aging Ment Health. 2015;19(5):418-29.

12. Yuasa M, Ukawa S, Ikeno T, Kawabata T. Multilevel, cross-sectional study on social capital with psychogeriatric health among older Japanese people dwelling in rural areas. Australasian J Ageing. 2014;33(3):E13-9.

13. Wang $R$, Xue D, Liu Y, Chen H, Qiu Y. The relationship between urbanization and depression in China: the mediating role of neighborhood social capital. Int J Equity Health. 2018;17(1):105.

14. Lee HJ, Lee DK, Song W. Relationships between Social Capital, Social Capital Satisfaction, Self-Esteem, and Depression among Elderly Urban Residents: Analysis of Secondary Survey Data. Int J Environ Res Public Health. 2019;16:8. 
15. Anhui Statistical Yearbook 2017 [http://tj].ah.gov.cn/oldfiles/tij/ttjweb/ttnj/2 017/cn.html].

16. Bai Z, Wang Z, Shao T, Qin X, Hu Z. Relationship between individual social capital and functional ability among older people in Anhui Province, China. Int J Environ Res Public Health. 2020;17(8):2775.

17. Grootaert C, Narayan D, Jones VN, Woolcock M. Measuring social capital: An integrated questionnaire: the World Bank; 2004.

18. Hu F, Niu L, Chen R, Ma Y, Qin X, Hu Z. The association between social capital and quality of life among type 2 diabetes patients in Anhui province, China: a cross-sectional study. BMC Public Health. 2015;15:786.

19. Bartko JJ. The Intraclass correlation coefficient as a measure of reliability. Psychol Rep. 1966;19(1):3-11.

20. Biggs JT, Wylie LT, Ziegler VE. Validity of the Zung self-rating depression scale. Brit J Psychiatry. 1978;132:381-5.

21. Zung WWK. A self-rating depression scale. Arch Gen Psychiatry. 1965;12(1): 63-70.

22. Albert SM. Social determinants of geriatric depression. Am J Geriatric Psychiatry. 2016;24(12):1209-10.

23. Wu Y, Lei P, Ye R, Sunil TS, Zhou H. Prevalence and risk factors of depression in middle-aged and older adults in urban and rural areas in China: a cross-sectional study. Lancet. 2019;394:S53.

24. Çamdeviren H, Mendes M, Ozkan MM, Toros F, Sasmaz T, Oner S. Determination of depression risk factors in children and adolescents by regression tree methodology. Acta Med Okayama. 2005;59(1):19-26.

25. D'Alisa S, Miscio G, Baudo S, Simone A, Tesio L, Mauro A. Depression is the main determinant of quality of life in multiple sclerosis: a classificationregression (CART) study. Disabil Rehabil. 2006;28(5):307-14.

26. Loh W-Y. Classification and regression trees. Wiley Interdisciplinary Reviews: Data Mining and Knowledge Discovery. 2011;1(1):14-23.

27. Wu TL, Hall BJ, Canham SL, Lam Al. The association between social capital and depression among Chinese older adults living in public housing. J Nerv Ment Dis. 2016;204(10):764-9.

28. Cohen-Cline H, Beresford SA, Barrington W, Matsueda R, Wakefield J, Duncan GE. Associations between social capital and depression: a study of adult twins. Health \& place. 2018;50:162-7.

29. Haseda M, Kondo N, Ashida T, Tani Y, Takagi D, Kondo K. Community social capital, built environment, and income-based inequality in depressive symptoms among older people in Japan: An ecological study from the JAGES project. J Epidemiology. 2018;28(3):108-16.

30. Joe W, Perkins JM, Subramanian SV. Community involvement, trust, and health-related outcomes among older adults in India: a population-based, multilevel, cross-sectional study. Age Ageing. 2019; 48(1):87-93.

31. An S, Jang Y. The role of social capital in the relationship between physical constraint and mental distress in older adults: a latent interaction model. Aging Ment Health. 2018;22(2):245-9.

32. Chiao C, Weng L-J, Botticello AL. Social participation reduces depressive symptoms among older adults: An 18-year longitudinal analysis in Taiwan. BMC Public Health. 2011;11(1):292.

33. Chola L, Alaba O. Association of neighbourhood and individual social capital, neighbourhood economic deprivation and self-rated health in South Africa--a multi-level analysis. PLoS One. 2013;8(7): e71085.

34. Pridmore P, Thomas L, Havemann K, Sapag J, Wood L. Social capital and healthy urbanization in a globalized world. J Urban Health. 2007;84(3 Suppl): i130-43.

35. Miao J, Wu X, Sun X. Neighborhood, social cohesion, and the Elderly's depression in Shanghai. Social Sci Med (1982). 2019;229:134-43.

36. Liu Y, Liu J, Zhou Y. Spatio-temporal patterns of rural poverty in China and targeted poverty alleviation strategies. J Rural Stud. 2017; 52:66-75.

37. Watanabe R, Kondo K, Saito T, Tsuji T, Hayashi T, Ikeda T, Takeda T. Change in Municipality-Level Health-Related Social Capital and Depressive Symptoms: Ecological and 5-Year Repeated Cross-Sectional Study from the JAGES. Int J Environ Res Public Health. 2019;16:11.

38. Han S, Lee HS. Social capital and depression: does household context matter? Asia-Pacific J Public Health. 2015;27(2):Np2008-18.

39. Pickett KE, Pearl M. Multilevel analyses of neighbourhood socioeconomic context and health outcomes: a critical review. J Epidemiol Community Health. 2001;55(2):111-22.

\section{Publisher's Note}

Springer Nature remains neutral with regard to jurisdictional claims in published maps and institutional affiliations.

\section{Ready to submit your research? Choose BMC and benefit from:}

- fast, convenient online submission

- thorough peer review by experienced researchers in your field

- rapid publication on acceptance

- support for research data, including large and complex data types

- gold Open Access which fosters wider collaboration and increased citations

- maximum visibility for your research: over $100 \mathrm{M}$ website views per year

At BMC, research is always in progress.

Learn more biomedcentral.com/submissions 